\title{
Effect of Different Solvents in Solvent Casting of Porous Pla Scaffolds - In Biomedical and Tissue Engineering Applications
}

\author{
Mousam Choudhury ${ }^{1}$, Smita Mohanty ${ }^{1 *}$ and Sanjay Nayak ${ }^{1,2}$ \\ ${ }^{1}$ Laboratory for Advanced Research in Polymeric Materials (LARPM), Bhubaneswar, Odisha, India \\ ${ }^{2}$ Central Institute of Plastics Engineering and Technology (CIPET), Chennai, Tamil Nadu, India
}

*Corresponding Author: Smita Mohanty, Laboratory for Advanced Research in Polymeric Materials (LARPM), Bhubaneswar, Odisha, India, Tel: 0674 2742852, 2740173;Fax: 0674 2740463; Email: papers.journal@gmail.com

Rec date: July25, 2014, Acc date: October 29, 2014, Pub date: November 3, 2014

Copyright: (c) 2014 Choudhury M et al. This is an open-access article distributed under the terms of the Creative Commons Attribution License, which permits unrestricted use, distribution, and reproduction in any medium, provided the original author and source are credited.

\begin{abstract}
In the present investigation, PLA porous scaffolds was fabricated using $\mathrm{NaCl}$ as porogen in three different solvents i.e. 1,1,1,3,3,3-hexafluoro-2-propanol (HFIP), dichloromethane (DCM) and chloroform (CF) respectively, by solvent casting particulate leaching method. The morphology, structure and thermal behaviour of the PLA scaffolds for porosity measurement were evaluated using scanning electron microscopy (SEM), Fourier transform infrared spectroscopy (FTIR); thermo gravimetric analysis (TGA) and differential scanning calorimetry (DSC). The developed porous scaffolds were further characterized for porosity measurement, solvent uptake property and water absorption capacity at different temperatures. PLA/ CF scaffold depicted higher porosity factor (93\%) along with enhanced water uptake capacity $(220 \%)$ as against PLA/ HFIP scaffold $(75 \%)$. However PLA/ DCM scaffolds illustrated more thermal stability as compared with PLA/ HFIP and PLA/ CF scaffolds.
\end{abstract}

Keywords: PLA; Biodegradable; Scaffolds; FTIR; Solvent casting technique; Water uptake

\section{Introduction}

Tissue engineering is an interdisciplinary field that applies the principles of engineering and life science towards the development of biological substitutes that restore, maintain and or improve tissue function. The production of an engineered tissue starts by the design and the formation of a structure able to support the migration and growth of cells that will originate in new tissue. These structures are characterized by an interconnected pore network able that enables core penetration of the growing cells, and withers away after the degradation of the scaffold [1,2]. Scaffolds should be biodegradable allowing extracellular matrix (ECM) to occupy the void space when the biomaterial is degraded. For tissue scaffolds, it is important that the plastic be porous, to allow for cell attachment and growth, and for nutrient diffusion through the scaffold as the cells are growing into it There are several ways of generating pores. Salt leaching entails mixing the plastic with grains of a salt, shaping it into the desired form and letting it cool, with subsequent soaking in water to dissolve the salt leaving behind the pores [4]. Biodegradable polymers such as poly (glycolic acid), poly (lactic acid) and their copolymers, poly ( $\mathrm{p}$ dioxanone), and copolymers of trimethylene carbonate and glycolide have been extensively used in a number of clinical applications [10].

Poly(lactic acid) (PLA) belongs to the family of aliphatic polyesters commonly made from $\alpha$ - hydroxy acids, which include polyglycolic acid or polymandelic acid, and are considered biodegradableandcompostable[5].PLAisathermoplastic,high-

strength,high-modulus polymer that can be made from annually renewable resources to yield articles for use in either the industrial packaging field or the biocompatible/ bio-absorbable medical device market. The polymer is produced through ring-opening polymerization of lactic acid. Since lactic acid is a chiral molecule, it exists in two forms, D-PLA and L-PLA. It is known that the properties of PLA are highly affected by the stereo-isomeric L/D ratio of the lactate units [6]. Also, PLA has a degradation time in the environment in the order of six months to two years, as compared to 500 to 1000 years for conventional plastics such as polystyrene (PS) and polyethylene (PE).

High-molecular-weight poly (lactic acid) is a colorless, glossy, stiff thermoplastic polymer with properties similar to polystyrene. The amorphous PLA is soluble in most organic solvents such as tetrahydrofuran (THF), chlorinated solvents, benzene, acetonitrile, and dioxane [6]. However, when multiangle light scattering (MALS) technique is used for determining, independently, the absolute molar mass and the average size of particles in solution, by scattering light, the most appropriate solvent found so far for PLA is assumed to be 1,1,1,3,3,3-hexafluoro-2-propanol (HFIP) [7, 8]. This appropriateness is majorly due to the acceptable difference in refractive index values between PLA (1.44) and solvent HFIP (1.275) [6]. Similarly, because PLA has a similar refractive index to chloroform and tetrahydrofuran, the refractive index increments for PLA in these two solvents are too low to report, as compared to hexafluoroisopropanol (HFIP). Further, remaining solvents like dichloromethane, chloroform also find wide exposure in dissolving PLA and tailor-making the polymer for various end-use applications, scaffolds etc $[9,11]$. Nowadays, there are many techniques that realize scaffolds with suitable biocompatibility. Among them, solvent casting/ particulate leaching allows the control of microstructural characteristics such as porosity, pore size and pore interconnection degree [3].

In this study, PLA scaffolds are fabricated using different solvents like hexa-fluoroisopropanol (HFIP), dichloromethane (DCM) and chloroform (CF), by solvent casting particulate leaching method. PLA scaffolds have been developed using salt or sugar as porogen, or entrapped $\mathrm{CO}_{2}$ gas bubbles for generating required density of pores in the porous scaffold. The effect of different solvent in fabrication of 
porous biodegradable scaffold has been highlighted. The scaffolds were subjected to numerous tests like solvent uptake, porogen leaching, and density and porosity measurements to evaluate performance characteristics. Various in-depth characterization studies like SEM, DSC, TGA have also been included.

\section{Materials and Methods}

\section{Raw Materials}

Poly lactic acid (PLA) grade 4042D (having molecular weight $\mathrm{Mw}$ $6,00,000)$, was purchased from Nature Works, USA. The solvents used of AR grade, hexafluoroiso propanol $(1,1,1,3,3$,3-hexafluoro-2propanol) and dichloromethane were purchased from M/s SigmaAldrich and $\mathrm{M} / \mathrm{s}$ Fisher scientific respectively. The pore size range controlled using $\mathrm{NaCl}$ particles as porogen (having diameter $250-425 \mu \mathrm{m})$ was purchased from M/s Fisher Scientific. Moulds for scaffolds were manufactured at site and used for PLA scaffolding.

\section{Methods: Characterization techniques}

Fabrication of PLA scaffolds by Solvent casting particulate leaching method: Scaffolds were produced by means of solvent casting/ particulate leaching technique. PLA was dissolved in the solvent (hexafloroiso propanol/ dichloromethane/ chloroform), by stirring for about three hours at room temperature. To create the pores into the scaffold, $\mathrm{NaCl}$ crystals were employed as porogen, sieved to a specific size range $(150-300 \mu \mathrm{m})$, added and homogeneously mixed to the polymer solution at a particular weight ratio of $10 \mathrm{wt} \%$ loading. The viscous polymer solution was then casted on Teflon molds $(10 \mathrm{~mm}$ diameter, $3 \mathrm{~mm}$ thickness) and dipped in ethanol for about two hours at room temperature, to separate the solvent. The $\mathrm{PLA} / \mathrm{NaCl}$ composite was then leached in de-ionized water for 24 hours in vacuum oven at $70^{\circ} \mathrm{Ctemperature,} \mathrm{and} \mathrm{regularly} \mathrm{checked} \mathrm{at} \mathrm{an} \mathrm{interval}$ of 4 hours to remove the porogen and create voids into the scaffold. The resulting porosity can be varied in a controlled way and changed as the pore size is dependent on the size of the salt crystals. The resulting porous scaffolds were freeze-dried at $-50^{\circ} \mathrm{C}$ in an environmental chamber to obtain porous scaffolds for further characterization.

Fourier Transform Infrared Spectroscopy (FTIR): Chemical analysis of PLA scaffolds have been performed by total reflectance Fourier transform infrared spectroscopy (Nicolet 6700 spectrophotometer, Thermo Scientific, USA). The analysis was conducted to identify the deviation in functional group, if any; when PLA scaffolds were fabricated using three different solvents The FTIR spectrum was obtained by adding 64 consecutive scans with a resolution of $2 \mathrm{~cm}^{-1}$ within the range of $400-4000 \mathrm{~cm}^{-1}$.

Differential scanning calorimetry (DSC): DSC thermograms have been taken for the samples using a standard aluminum pan, in a differential scanning calorimeter (Q20, M/s TA instruments, USA). Nitrogen was used as a sweeping gas, and the heating rate was maintained at $10^{\circ} \mathrm{C} / \mathrm{min}$. Samples (5 to $10 \mathrm{mg}$ ) were loaded without further treatment. The initial and final temperatures were taken as ambient and $240^{\circ} \mathrm{C}$, respectively. All the samples for DSC analysis were original PLA/ HFIP, PLA/ DCMand PLA/ CF scaffolds without any other loading and modification.

Thermogravimetric Analysis (TGA): The thermal stability of PLA scaffolds has been studied employing thermo gravimetric analysis (TGA; Q50, TA Instruments, USA). The samples were scanned from $50^{\circ} \mathrm{C}$ to $500^{\circ} \mathrm{C}$ at a rate of $10^{\circ} \mathrm{C} / \mathrm{min}$ under $\mathrm{N} 2$ atmosphere. Corresponding degradation temperatures and percentage char have been reported.

Hydration of PLA scaffolds in ionic water: The water uptake capacity of PLA scaffold was determined by the hydration of the sample in deionized water at room and elevated temperature i.e. $25^{\circ} \mathrm{C}$ and $37^{\circ} \mathrm{C}$ respectively. The round shape specimens with diameter about $2 \mathrm{~cm}$ (approx) were placed in deionized water for a required period of time. Prior to immersion, the specimens were weighed in dry condition and the weight was noted as M. After 24 hours of immersion, the hydrated samples were taken and weighed on an electronic balance, after blotting the surface water with a filter paper, to get Mwet. The percentage water uptake of the PLA/ HFIP/ DCM/ CF scaffolds was calculated as follows:

\section{Water uptake $(\%)=100 \times($ Mwet-M $) / M \quad$ (equation 1$)$}

Where Mwet and $\mathrm{M}$ are the weights of wet and dried scaffolds, respectively. The hydration experiment was repeated 3 times, for both the temperatures and the average value was taken as the percentage water uptake at $25^{\circ} \mathrm{C}$ and $37^{\circ} \mathrm{C}$.

Solvent uptake capacity of PLA scaffolds: PLA scaffolds were also immersed in an isotonic solution, which has the same concentration as present in the blood or cells of body. Saline solution is a common example of isotonic solution and phosphate buffered saline (PBS) is a buffer solution commonly used in biological research. PLA/ HFIP/ $\mathrm{DCM} / \mathrm{CF}$ scaffold samples were dipped and monitored for solvent uptake property in a water-based salt solution (PBS) containing sodium chloride, sodium phosphate at metered levels. The temperature was maintained at room and elevated temperature i.e. $25^{\circ} \mathrm{C}$ and $37^{\circ} \mathrm{Crespectively} \mathrm{for} \mathrm{duration} \mathrm{of} 24$ hours.

Porogen Leaching Test: The porogen leaching was performed at room temperature in beakers filled with de-ionized water. The presence of $\mathrm{NaCl}$ (porogen) content after every 4 hours was titrated by silver nitrate solution, to check the (\%) of porogen leached out from the scaffold. The leaching process was performed for total 24 hours.

Density and porosity of PLA scaffolds: The porosity (P) of the scaffolds was calculated by measuring the volume of scaffold (Vs) and volume of pore (Vp) of the PLA/ HFIP/ DCM/ CF scaffolds. Vs was calculated using scaffold geometry i.e. length, width and height, using ethanol infiltration method. The weighed scaffolds (W0) were incubated in absolute ethanol at room temperature. The system was maintained for $15 \mathrm{~min}$ in desiccators under reduced pressure to remove air bubbles. The scaffolds were taken out and wiped superficially with a filter paper to remove the surface ethanol, and then weighed immediately (We). Vp was defined as (We - W0)/ qe, where qe $(0.789 \mathrm{mg} / \mathrm{ml})$ represents the ethanol density at room temperature. The porosity of the scaffolds was calculated according to the following equation:

$$
\mathrm{P}(\text { in } \%)=(\mathrm{Vp} / \mathrm{Vs}) \times 100 \quad \text { (equation } 2)
$$

Further, the apparent density of the scaffolds was calculated as W0/ Vs, where is the weight of scaffolds without immersing in any solvent.

Scanning Electron Microscopy (SEM): PLA scaffolds using different solvents were studied for their pore structure (e.g. pore size and pore interconnection) using Scanning Electron Microscopy. Prior to SEM analysis, samples were prepared by cutting with a sterilized blade and mounting onto aluminum stubs with a carbon tape. The mounted samples were further coated with a gold using a vacuum sputter coater 
Citation: Choudhury M, Mohanty S, Nayak S (2014) Effect of Different Solvents in Solvent Casting of Porous Pla Scaffolds - In Biomedical and Tissue Engineering Applications. J Tissue Sci Eng 6: 142. doi:10.4172/2157-7552.1000142

Page 3 of 7

prior to test to improve the surface conductivity. The porous structures of the scaffolds were then examined using a Scanning Electron Microscope (EVMA-15 Carl Zeiss, UK) with an acceleration voltage of $15 \mathrm{kV}$.

\section{Results and Discussion}

\section{Fourier Transform Infrared Spectroscopy (FTIR)}

Fourier Transform Infrared Spectroscopy (FTIR) spectrum of PLA (HFIP/DCM/CF) scaffolds depicts the chemical structure and presence of several functional groups, as shown in Table 1.

\begin{tabular}{|l|l|}
\hline Wave number $\left(\mathrm{cm}^{-1}\right)$ & Functional group \\
\hline $1753 \mathrm{~cm}^{-1}$ & (C=O stretching) \\
\hline $1451 \mathrm{~cm}^{-1}$ & (C-H stretching) \\
\hline $3423 \mathrm{~cm}^{-1}$ & (O-H stretching) \\
\hline $1180 \mathrm{~cm}^{-1}$ & C-C(O)-C stretching \\
\hline $1080 \mathrm{~cm}^{-1}$ & (C-O stretching) \\
\hline
\end{tabular}

Table 1: Wave number and functional group present in the pla scaffolds

All the scaffolds prepared exhibited identical peak, which indicates no change in the chemical structure irrespective of variations in the solvents. The typical absorption peak at $1753 \mathrm{~cm}^{-1}$ tol751 $\mathrm{cm}^{-1}$, corresponds to $\mathrm{C}=\mathrm{O}$ stretching whereas the peak at $1451 \mathrm{~cm}^{-1}$ indicates $-\mathrm{CH}$ Stretching (Figure 1).

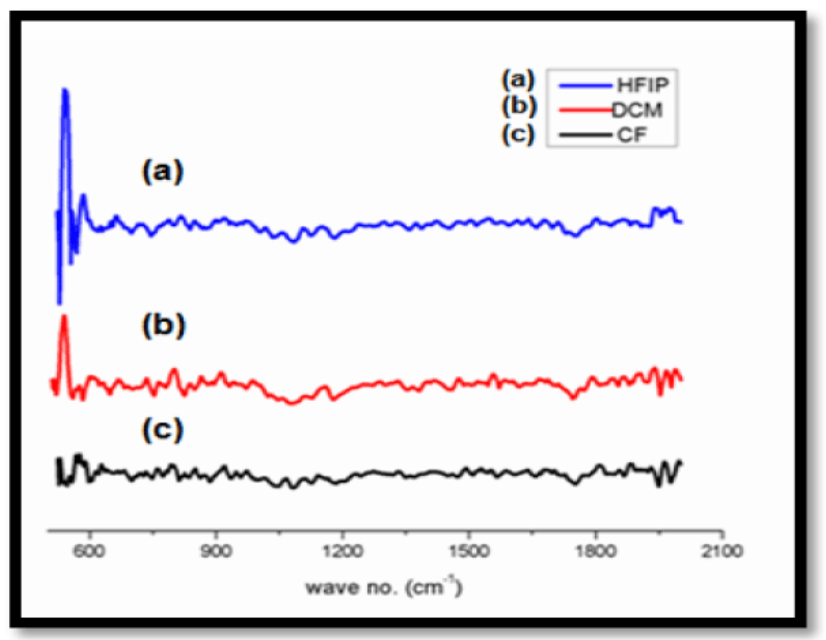

Figure 1: FTIR of PLA (HFIP/DCM/CF) scaffolds

\section{Differential scanning calorimetry (DSC)}

PLA is generally categorized as a stiff polymer at room temperature. The glass transition temperature (Tg) is typically between $55-65^{\circ} \mathrm{C}$. The melting temperature (Tm) of PLA containing either the L- or Disomeric form alone, is $155-165^{\circ} \mathrm{C}$. The DSC scans for PLA scaffold casted in different solvents are revealed in Table 2.

\begin{tabular}{|l|l|l|}
\hline Sample name & $\operatorname{Tg}\left({ }^{\circ} \mathrm{C}\right)$ & $\operatorname{Tm}\left({ }^{\circ} \mathrm{C}\right)$ \\
\hline PLA(HFIP) & 62.55 & 151 \\
\hline PLA(DCM) & 62 & 153 \\
\hline PLA(CF) & 63 & 152 \\
\hline
\end{tabular}

Table 2: Thermal properties of pla (hfip/dcm/cf) scaffolds

DSC scan in Figure 2 shows that the melting point of PLA (HFIP) scaffolds at $151.41^{\circ} \mathrm{C}$ is little lower than that of the melting temperature of PLA (DCM) and PLA (CF) scaffolds. The Tg of the PLA (HFIP/DCM/CF) was found to increase from $62.55^{\circ} \mathrm{C}$ to $63.54^{\circ} \mathrm{C}$.

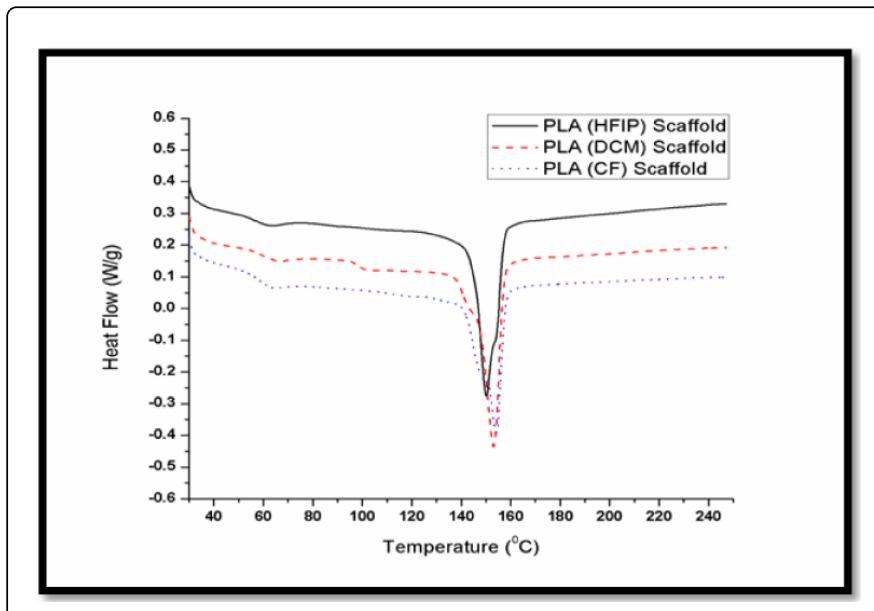

Figure 2: Heat flow versus temperature of PLA (HFIP/DCM/CF) scaffold

\section{Thermogravimetric Analysis (TGA)}

Degradation of scaffolds can be attributed to many formations, factors, thermal temperature one of the most important factors towards the PLA (HFIP/DCM/CF) scaffolds. Table 3 shows the thermal stability of PLA scaffolds fabricated using HFIP, DCM and CF as solvents.

\begin{tabular}{|l|l|l|l|}
\hline Sample name & $\begin{array}{l}\text { Initial degradation } \\
\text { temperature }\left({ }^{\circ} \mathrm{C}\right)\end{array}$ & $\begin{array}{l}\text { Degradation at } \\
50 \% \text { wt. loss }\end{array}$ & $\begin{array}{l}\text { Final degradation } \\
\text { temperature }\left({ }^{\circ} \mathrm{C}\right)\end{array}$ \\
\hline PLA(HFIP) & 257.14 & 327.08 & $353.68 \mathrm{~s}$ \\
\hline PLA(DCM) & 270.28 & 338.34 & 361.71 \\
\hline PLA(CF) & 257.14 & 343.84 & 368.69 \\
\hline
\end{tabular}

Table 3: Initial degradation temperature \& final degradation

The thermal degradation was studied by TGA analysis, and Table 3 shows the degradation as different intervals of weight loss by TGA thermogram having weight loss Vs temperature. PLA/DCM showed higher thermal stability for initial thermal degradation (T1) $270^{\circ} \mathrm{C}$, as compared to PLA/HFIP and PLA/CF having thermal stability at $257^{\circ} \mathrm{C}$.

The TGA curve of PLA (HFIP/DCM/CF) scaffolds shown in Figure 3. However the initial and maximum thermal degradation temperature 
Citation: Choudhury M, Mohanty S, Nayak S (2014) Effect of Different Solvents in Solvent Casting of Porous Pla Scaffolds - In Biomedical and

Page 4 of 7

of PLA (CF) was higher than those of PLA (HFIP) and PLA (DCM) scaffolds.

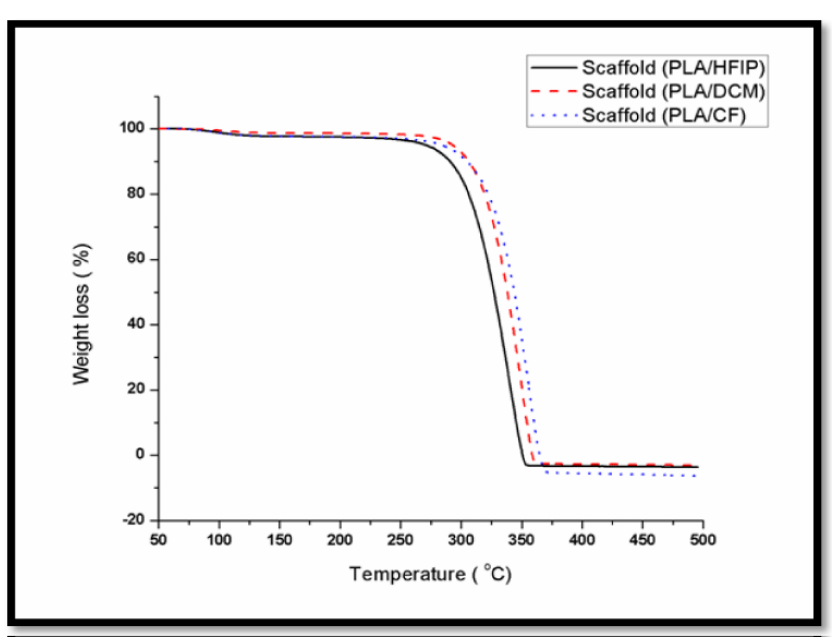

Figure 3: Weight loss (\%) versus temperature of PLA (HFIP/DCM/CF) scaffolds

\section{Hydration of PLA scaffolds in ionic water}

Figure 4 depicts the water uptake of scaffolds by three different solvents. As the porous scaffolds have a characteristic pore due to which the uptake of water can be best explained due to the increase of surface area to volume ratio of PLA (HFIP/DCM/CF) scaffolds as the sizes of micro pores are of few microns. Moreover, these results indicate that the micro pores created by this technique are accessible to water.



Figure 4: Water uptake capacity (\%) of PLA (HFIP/DCM/CF) scaffolds

So it is clear that the increase the temperature of the water, there is an increase the water uptake capacity (\%) because the hot water molecule observed a higher encroachment that explains faster penetration into the PLA (HFIP/DCM/CF) scaffolds. With increase the temperature the collision of each water molecule to other increase, due to which there is a further increase in velocity and collision, there by an increase in energy. This lead to easy penetration of these water molecules as high temperature into the pore and micropores of the scaffold, thereby increase the penetration of water uptake. PLA/HFIP having a high density and lower porosity (91\%) showed lower water uptake capacity of $75 \%$ as room temperature whereas PLA/CF observed the highest water uptake capacity, $220 \%$ and $290 \%$ at room temperature $\left(25^{\circ} \mathrm{C}\right)$ and $37^{\circ} \mathrm{C}$ respectively.

The fractional water-uptake curves as a function of PLA content and type of polyesters are shown in Figure 4. As the PLA scaffold, the water uptake increased and the time required to achieve the equilibrium water content increased. This is primarily due to the presence of hydroxyl groups on the PLA moiety, which is the most probable site for accommodation of the additional water. However, the PLA (CF) scaffold shows higher water absorption than that of the PLA (HFIP/DCM), probably due to its porous structure.

\section{Solvent uptake capacity of PLA scaffolds}

Figure 5 enumerates the uptake of phosphate buffer solution (PBS), for PLA scaffolds immersed in PBS solution at room temperature and elevated temperature $\left(37^{\circ} \mathrm{C}\right)$.

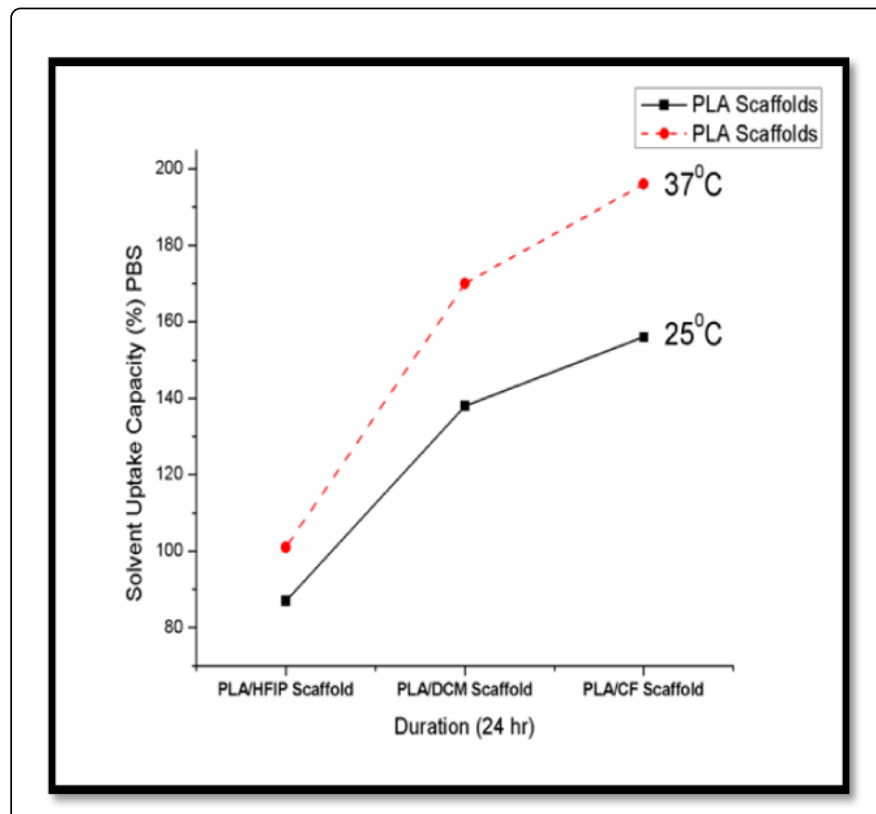

Figure 5: Solvent uptake capacity (\%) of PLA (HFIP/DCM/CF) scaffolds

The solvent uptake property of PLA scaffold was monitored at two different temperatures i.e. $25^{\circ} \mathrm{C}$ and $37^{\circ} \mathrm{C}$, for 24 hours. Figure 5 indicates the solvent uptake properties of three scaffolds at $25^{\circ} \mathrm{C}$ increase with respect to time and increase the temperature. The scaffolds observed an increase in absorption behavior in presence of phosphate buffer solution (of stable $\mathrm{pH}$ ), with increase in temperature. This increase may be attributed due to the increased velocity of the solvent molecules that gain energy and collides which each other thereby imparting more penetration to the porous structures, as compared to the behavior at $25^{\circ} \mathrm{C}$. The porosity of three scaffolds 
Citation: Choudhury M, Mohanty S, Nayak S (2014) Effect of Different Solvents in Solvent Casting of Porous Pla Scaffolds - In Biomedical and Tissue Engineering Applications. J Tissue Sci Eng 6: 142. doi:10.4172/2157-7552.1000142

Page 5 of 7

along with the solvent uptake properties, increased, as shown in Figure 5. As observed earlier, at $25^{\circ} \mathrm{C}$, PLA/HFIP exhibited an average water uptake capacity of $75 \%$ as against an increased PBS uptake at $83 \%$.

\section{Porogen Leaching Test}

The leaching processes was carried out at equal intervals of $4 \mathrm{hr}$, until further addition of $0.1 \mathrm{~N}$ silver nitrate in distilled water did not yield any precipitate in rinsed water. The porogen leaching test is a stable procedure in identifying the ease at which the scaffold remains porous with the leaching of fillers or porogen. Table 4 enumerates the percentage leach out from respective scaffold fabricated using three solvents.

\begin{tabular}{|l|l|l|l|l|l|}
\hline \multicolumn{2}{|c|}{ PLA(HFIP)Scaffolds } & \multicolumn{2}{c|}{ PLA(DCM)Scaffolds } & \multicolumn{2}{c|}{ PLA(CF)Scaffolds } \\
\hline \multicolumn{1}{|c|}{ SaltLeach-out (\%) } & Time(hr) & \multicolumn{1}{|c|}{ SaltLeach-out (\%) } & Time(hr) & SaltLeach-out (\%) \\
\hline 4 & 33.33 & 4 & 36 & 4 & 33 \\
\hline 8 & 26.66 & 8 & 25.66 & 8 & 27.48 \\
\hline 12 & 20 & 12 & 19 & 12 & 18.55 \\
\hline 16 & 13.33 & 16 & 13.66 & 16 & 14.65 \\
\hline 20 & 6.67 & 20 & 5.68 & 20 & 6.32 \\
\hline 24 & 0 & 24 & 0 & 24 & 0 \\
\hline
\end{tabular}

Table 4: Porogen leaching test

The porogen leach-out process follows a steady path in case of PLA (HFIP), within in there was accurate dimension of porogen at the rate of $6.67 \%$ at every step of 4 hours. On an average the porous scaffolds showed maximum leaching within 12 hours of stirring. After 12 hours, Figure 6 observed a gradual decrease in the slope of leaching, for all scaffolds.

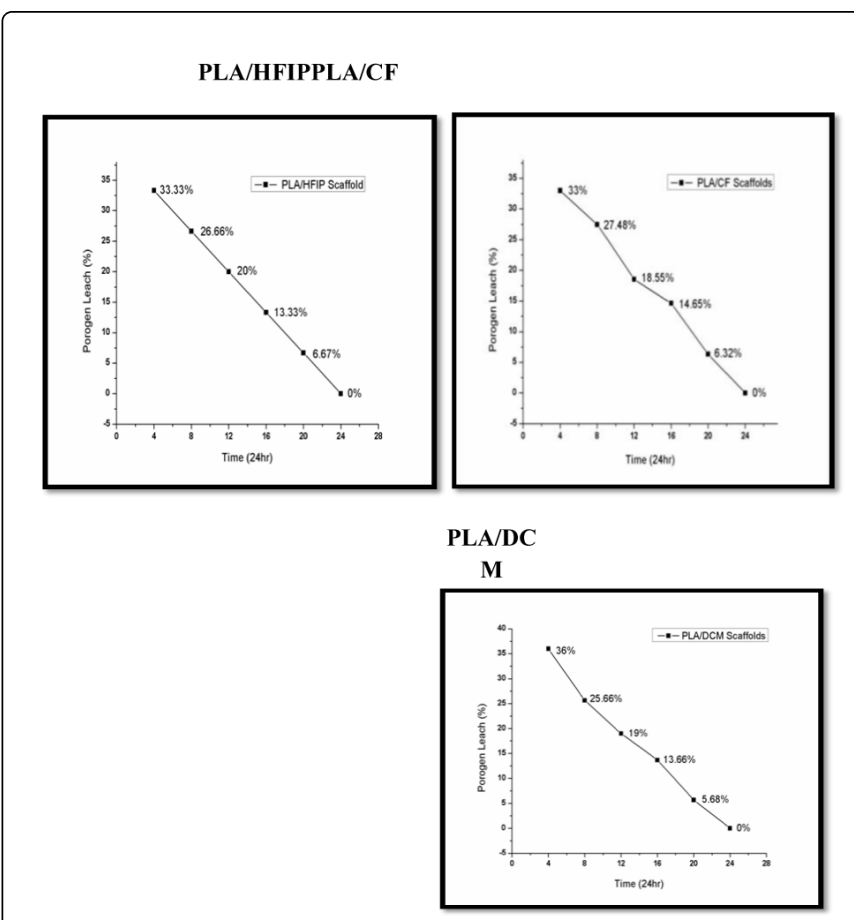

Figure 6: Porogen leaching Test (at room temperature) for PLA (HFIP/DCM/CF)
Further, the other two were observed to be none risen for PLA (DCM) and PLA (CF) scaffolds due to the difference of leaching being $5 \%$ to $8 \%$. The possible reaction scheme when $\mathrm{AgNO}_{3}$ is added to the solution, it reacts with $\mathrm{NaCl}$ as given in equation 3 3)

$\mathrm{AgNO}_{3}(\mathrm{~s})+\mathrm{Na}^{+}(\mathrm{aq})+\mathrm{Cr}(\mathrm{aq}) \rightarrow \mathrm{AgCl}(\mathrm{s})+\mathrm{Na}^{+}(\mathrm{aq})+\mathrm{NO}_{3}{ }^{-}(\mathrm{aq})$ (equation

The complete leaching of $\mathrm{NaCl}$ from the scaffold is achieved by addition of $\mathrm{AgNO}_{3}$ into the leached out solvent. This explains the random monomer of porogen from the scaffold at room temperature $\left(25-30^{\circ} \mathrm{C}\right)$ due to non-adhesion of the sodium and chloride atom while getting hydrated in polar water $\left(\mathrm{H}_{2} \mathrm{O}\right)$ molecules.

\section{Density and porosity of PLA scaffolds}

The specific gravity of PLA fibers having a circular cross-section is $1.25 \mathrm{~g} / \mathrm{cm}^{3}$ i.e. lower than natural fibers [12]. However, scaffolds having a porous structure are bound to have lower density as compared to electrospun PLA fibers.

Table 5 shows the density of the different scaffold prepared using HFIP, DCM, CF solvents. PLA/HFIP showed high density at 0.11494 $\mathrm{gm} / \mathrm{cm}^{3}$ as compared to PLA/DCM and PLA/CFhaving 0.097 and $0.084 \mathrm{gm} / \mathrm{cm}^{3}$ respectively. The difference is density may depend on various factor like temperature, pressure, types of volume etc.

\begin{tabular}{|l|l|l|}
\hline Scaffolds(sample) & Density $\left(\mathbf{g} / \mathbf{c m}^{3}\right)$ & Porosity(\%) \\
\hline PLA(HFIP) & 0.11494 & 90.6 \\
\hline PLA(DCM) & 0.0974 & 92.1 \\
\hline PLA(CF) & 0.08361 & 93.3 \\
\hline
\end{tabular}

Table 5: Density \& porosity of pla (hfip/dcm/cf) scaffolds

In general density can be changed by changing either the pressure or the Increase the pressure always increases the density of a material. 
Increase the temperature generally decreases the density. Density may also depend upon its type of solvent/reagent used for dissolution the polymer. When PLA was dissolved in HFIP, DCM, CF, each of them had a different viscosity and chain flexibility. Thus, the further changes the compactness of the polymer the volume, there by increases the amorphousness' and densities the crystallinity for PLA/DCM, PLA/CF.
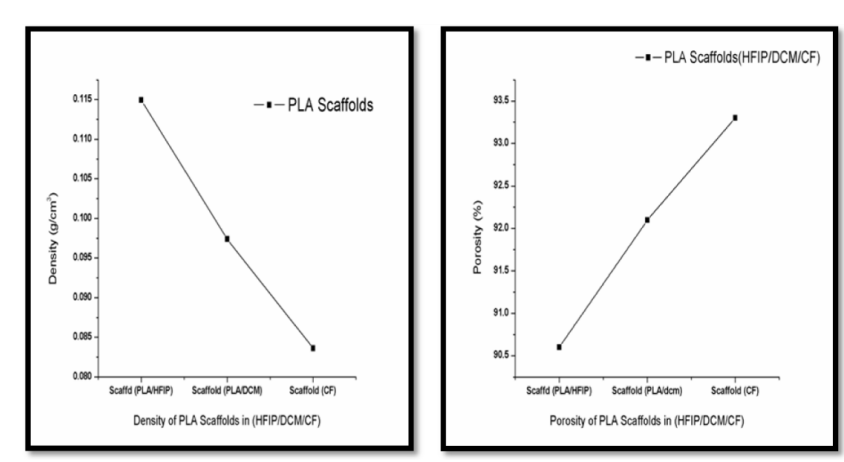

Figure 7: Density of PLA scaffolds in different solvents

As evident from Figure 7, with increase in density, there is a steady decrease in porosity of PLA/HFIP scaffolds, further, PLA/CF depicted the higher porosity in terms of last density, and hence the PLA scaffold followed the increase in proportionality i.e. porosity inversely proportional to density.

\section{Scanning Electron Microscopy (SEM)}

Figure 8 depicts scaffolds with $300-500 \mu \mathrm{m}$ pore size, produced by using suitable sieved salt crystals. SEM micrographs of three different PLA scaffolds, obtained in different scaffolds were achieved with different degrees of porosity.

According to SEM micrographs, for each scaffold typology, the surface and the cut section faces resembled a similar topological appearance as that of rocks at earth crust. The cut sections appeared to be more porous with a better pore interconnectivity degree.

As a whole, the data from the present study indicate that scaffolds produced with dichloromethane were different from scaffolds produced with the other solvents. Dichloromethane samples were generally stiffer, less permeable, and possessed more regular morphology than chloroform or hexafluro-Isopropanol samples. The Figure 8 shows that irregularities observable in the chloroform and hexafluro-Isopropanol scaffold microstructures likely increased the interconnectedness between pores and may have accounted for the higher permeability as compared to the Dichloromethane scaffolds. Likewise, the scaffold stiffness may have been increased by the regular, unit cell microstructure of the Dichloromethane scaffolds, as compared to the chloroform and hexafluro-Isopropanol scaffolds. Some variation was found between samples fashioned with the same solvent, which statistically obscured measurable effects of solvent treatments.

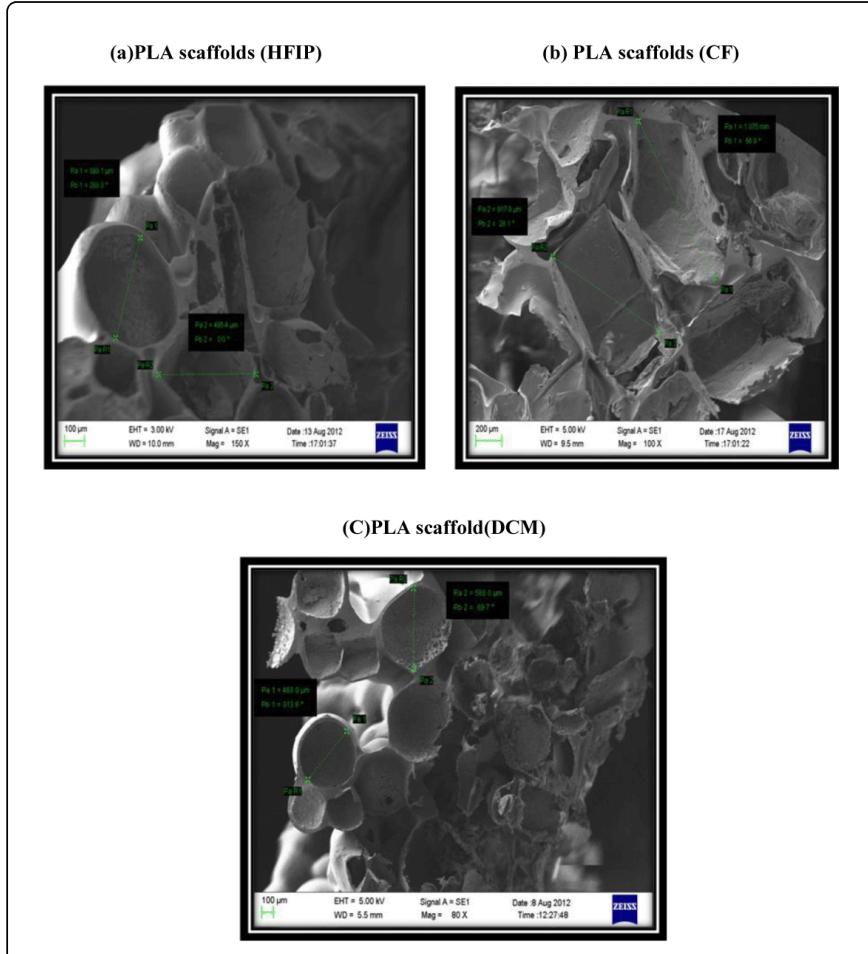

Figure 8: Representative scanning electron microscopy images of PLA scaffolds fabricated with (a) hexafluro-Isopropanol (b) chloroform (c) dichloromethane.

As shows dichloromethane, evaporated more than twice as fast as either chloroform or hexafluro-Isopropanol and SEM data show that dichloromethane, (rather than chloroform)produced specimens different from the other solvents suggests that the rate of solvent evaporation is more important in shaping the scaffold microstructure than the degree of polymer/solvent interactions alone. It is possible that the increased rate of evaporation in dichloro methane samples affected the polymer/solvent interactions through thermal mechanisms. For example, rapid evaporation of dichloromethane may have caused the formation of less porous polymer scaffold around the salt particles.

\section{Conclusion}

Solvent Casting/Particulate Leaching, among the various scaffolding techniques, stands out for its simplicity of operation, for the possibility of producing scaffolds with a good pore interconnectivity degree, controlled composition, porosity and pore size. High porosity and pore interconnectivity degree and a suitable pore size are key parameters that permit cells to penetrate in depth into the scaffold, and to produce a homogeneous cell/scaffold construct to be used as a tissue substitute in a biomedical application.

The scaffolds have been evaluated for various properties when these scaffolds were fabricated in three different solvents i.e. HFIP, DCM and CF solvents. Also, as porosity palsy a pivotal role in the process of generation of requisite crystallinity in scaffolds, different grade of porogen (salt) have been used to obtain a desired homogeneity in structure owing to its shape. The same has also been evaluated using lab grade salt (porogen pore diameter $300 \mu \mathrm{m}$ to $500 \mu \mathrm{m}$ ) and locally 
Citation: Choudhury M, Mohanty S, Nayak S (2014) Effect of Different Solvents in Solvent Casting of Porous Pla Scaffolds - In Biomedical and Tissue Engineering Applications. J Tissue Sci Eng 6: 142. doi:10.4172/2157-7552.1000142

Page 7 of 7

available common salt (porogen $\mathrm{NaCl}$, commercially available). The later was analyzed using Scanning Electron Microscope to depict its irregular structure, and pore size ranging from $500 \mu \mathrm{m}$ to $6000 \mu \mathrm{m})$. Figure 9 elaborates the differences in the porogen shape homogeneity, and hence the regular circular-structured lab grade porogen was used for further fabrication of scaffold.

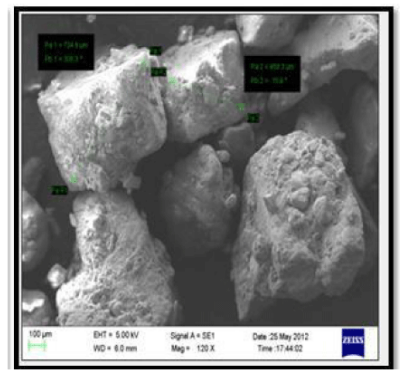

(a)

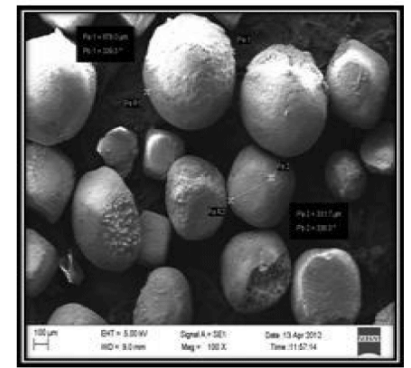

(b)
Figure 9: Porogen ( $\mathrm{NaCl}$ particles) with (a) common table salt and (b) lab grade salt

The PLA/ dichloromethane scaffolds represented a stiffer base as compared to PLA/ chloroform or PLA/ hexafluro-Isopropanol scaffolds. Also, when ensured for permeability, the PLA/ DCM depicted lower permeability and rugged morphology as compared to the other two. However, with similar content of porogen loading, the PLA/ chloroform scaffold showed highest porosity as compared to PLA/ DCM and PLA/ HFIP scaffolds;- a factor that benefits the requirements in bone-tissue engineering. Hence, chloroform can be taken as a better solvent to meet the homogeneity requirements of the scaffold due to its lower vapor pressure and slower evaporation time. Also, the cost effectiveness makes chloroform a preferred solvent along with its simplicity in hazards while handling the chemical.

This study can be further extended with calculations pertaining to difference in molecular weight, with variations in porogen loading, and hence the viscosity and scaffold flexibility can be further studied.

\section{References}

1. Pavia FC, La Carrubba V, Piccarolo S, Brucato V (2008) Polymeric scaffolds prepared via thermally induced phase separation: tuning of structure and morphology. J Biomed Mater Res A 86: 459-466.

2. Francesco Carfi Pavia, SalvatriceRigogliuso, Vincenzo La Carrubba, Gianluca Anotnio Mannella, Giulio Ghersi, et al. (2012) Poly Lactic Acid Based Scaffolds for Vascular Tissue Engineering. Chemical Engineering Transactions 27: 409-414.

3. F Intranuovo, E Sardella, R Gristina, M Nardulli, G Ceccone, et al. (2009) Plasma modification of PCL porous scaffolds fabricated by Solvent Casting/Particulate Leaching for Tissue Engineering. Plasma Processes and Polymers11: 184-195.

4. HadiHajiali, ShapourShahgasempour, M Reza Naimi-Jamal, HabibullahPeirovi, et al. (2011) Electrospun PGA/gelatin nanofibrous scaffolds and their potential application in vascular tissue Engineering. Int J Nanomedicine 6: 2133-2141.

5. Pham QP, Sharma U, Mikos AG (2006) Electrospinning of polymeric nanofibers for tissue engineering applications: a review. Tissue Eng 12: 1197-1211.

6. Donald Garlotta (2001) A Literature Review of Poly (Lactic Acid).Journal of Polymers and the Environment 9: 63-84.

7. Riemke van Dijkhuizen-Radersma, Lorenzo Moroni, Aart van Apeldoorn, Zheng Zhang, Dirk Grijpma (2008) Degradable polymers for tissue engineering. Tissue Engineering 193-221.

8. BL Seal, TC Otero, A Panitch (2001) Polymeric biomaterials for tissue and organ regeneration. Material Science \& Engineering 34: 147-230.

9. Sander EA, Alb AM, Nauman EA, Reed WF, Dee KC (2004) Solvent effects on the microstructure and properties of $75 / 25$ poly(D,L-lactideco-glycolide) tissue scaffolds. J Biomed Mater Res A 70: 506-513.

10. Gunatillake PA, Adhikari R (2003) Biodegradable synthetic polymers for tissue engineering. Eur Cell Mater 5: 1-16.

11. M Kiremitci-Gumusderelioglu, G Deniz (1999) Synthesis, Characterization and in Vitro Degradation of Poly(DL-Lactide)/ Poly(DL-Lactide-co-Glycolide) Films. Turk J Chem 23: 153-161.

12. DW Farrington, J Lunt, S Davies, RS Blackburn (2005) Poly(lactic acid) fibers. Biodegradable and Sustainable Fibres 6: 191-220. 